\title{
Laser Ablated Micromirrors for Printed Circuit Board Integrated Optical Interconnections
}

\author{
Nina Hendrickx, Student Member, IEEE, Jürgen Van Erps, Student Member, IEEE, \\ Geert Van Steenberge, Member, IEEE, Hugo Thienpont, Associate Member, IEEE, and \\ Peter Van Daele, Member, IEEE
}

\begin{abstract}
Optical interconnections offer a possible solution to the bandwidth problems associated with future electrical interconnections. Optics has proven its potential for long-haul communication networks, where it is today a well accepted standard. The integration towards shorter distances is challenging. Compatibility with technologies used in printed circuit board manufacturing is required to implement optical interconnections on board-level in the near future in a cost-effective way. Especially coupling structures, which are used to deflect the light beam over $90^{\circ}$, pose problems. We propose the use of metallized $45^{\circ}$ micromirrors which are fabricated with the use of laser ablation. This letter gives an overview of the fabrication process and shows experimental results. The root-mean-square surface roughness of the mirror facet is $70 \mathrm{~nm}$ or better, depending on the used polymer material. The $45^{\circ}$ angle can be ablated with an accuracy of $\pm 1 \circ$ and has a high reproducibility. The mechanical properties of the micromirrors were maintained after a Telcordia 85/85 stability test.
\end{abstract}

Index Terms-Coupling structures, laser ablation, micromirrors, optical interconnections.

\section{INTRODUCTION}

$\mathbf{O}$ PTICAL interconnections are a viable alternative for electrical interconnections in high-speed short-distance communication [1]. The integration to the board-level, covering distances of a couple of centimeters up to $1 \mathrm{~m}$, can be done with the help of a polymer optical layer, integrated on the printed circuit board (PCB). The polymer material has to withstand the high temperatures and pressures that occur during standard PCB manufacturing and soldering processes and should in addition show good optical properties at the aimed wavelength of $850 \mathrm{~nm}$.

The optical layer contains low-loss multimode optical waveguides to guide the light in the plane of the optical layer. Different technologies can be used for the structuring of the waveguides, such as photolithography [2], embossing [3], laser direct writing

Manuscript received December 22, 2006; revised February 26, 2007. The work of N. Hendrickx was supported by the Flemish Institute for the Promotion of Innovation by Science and Technology (IWT). This work was carried out in part within the framework of the Network of Excellence on Micro-Optics (NEMO) supported by the European Commission through FP6 Program.

N. Hendrickx, G. Van Steenberge, and P. Van Daele are with the Department of Information Technology, Ghent University, B-9052 Ghent, Belgium (e-mail: Nina.hendrickx@intec.ugent.be).

J. Van Erps and H. Thienpont are with the Department of Applied Physics, Vrije Universiteit Brussel, 1050 Brussels, Belgium.

Color versions of one or more of the figures in this letter are available online at http://ieeexplore.ieee.org.

Digital Object Identifier 10.1109/LPT.2007.897295
TABLE I

MAIN PROPERTIES OF THE USED OPTICAL MATERIALS

\begin{tabular}{|c||c|c|}
\hline & Truemode & Epocore \\
\hline Waveguide loss at $850 \mathrm{~nm}(\mathrm{~dB} / \mathrm{cm})$ & 0.04 & 0.2 \\
\hline Refractive Index Core at $850 \mathrm{~nm}$ & 1.5562 & 1.58 \\
\hline Refractive Index Cladding at $850 \mathrm{~nm}$ & 1.5422 & 1.57 \\
\hline Glass Transition Temperature $\left({ }^{\circ} \mathrm{C}\right)$ & 180 & $\geq 180$ \\
\hline
\end{tabular}

[4], and laser ablation [5]. Coupling structures are used to deflect the light beam over $90^{\circ}$ to couple light towards/from optoelectronic elements, such as photodiodes and VCSELs. A low coupling loss is required to maintain a high power budget. Different configurations can be considered for the $90^{\circ}$ beam deflection, such as grating couplers [6] and mirrors [7].

We propose the use of metallized $45^{\circ}$ micromirrors, which are integrated with the optical waveguides. The advantage of using these mirrors is the fact that they are wavelength independent, can be fabricated with a variety of technologies, and are highly reproducible. Laser ablation is used as enabling technology for the patterning of the micromirrors into the optical layer. Laser ablation is a very versatile micromachining technology and is fully compatible with PCB manufacturing; it is already used for the drilling of microvias into high density boards. This compatibility is an important requirement to come to a cost-effective solution.

\section{FABRICATION PROCESS}

Two different commercially available polymer materials are investigated for the optical layer: Truemode Backplane Polymer (Truemode) [8], a highly cross-linked acrylate-based material, and Epocore/Epoclad (Epocore) [4], an epoxy-based material. The Truemode material has been developed as an optical layer for the integration of optical interconnections to the board-level. Beside the excellent optical properties, it shows excellent thermal and environmental properties and is fully compatible with PCB manufacturing and soldering. The Epocore material is also fully compatible with PCB manufacturing and soldering but shows slightly higher optical losses. The price is, however, significantly lower, making it easily acceptable for introduction in mass production. Both polymer materials behave like a negative photoresist and can, therefore, also be patterned using standard photolithography. The main properties of both materials are given in Table I, the waveguide losses are given for photolithographic waveguides.

The optical layer, consisting of a cladding-core-cladding stack, is spin-coated on the FR4 substrate. The thickness of 


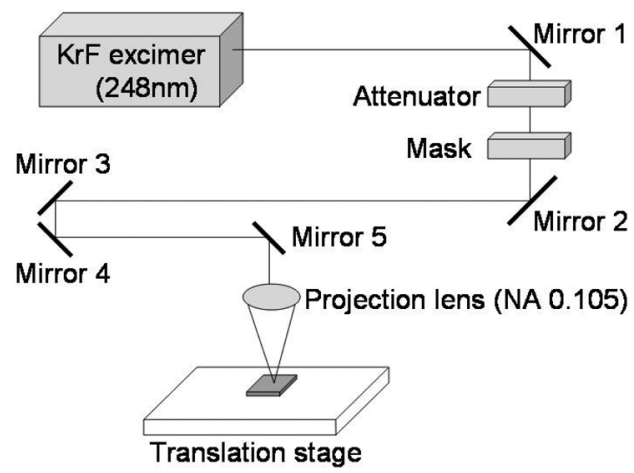

Fig. 1. Schematic of the excimer laser setup.

both the cladding and core layers is $50 \mu \mathrm{m}$. The cladding layers are UV flood exposed and cured. The core layer is either patterned photolithographically or by laser ablation, after UV flood exposure and curing of the layer.

The optical layer contains arrays of multimode waveguides with a cross section of $50 \mu \mathrm{m} \times 50 \mu \mathrm{m}$ at a pitch of $125 \mu \mathrm{m}$. The micromirrors are consequently patterned into the optical layer after the application of a top cladding layer on the patterned core layer. The alignment between the waveguides and the micromirrors is arranged prior to the ablation of the micromirrors with the help of Au alignment marks, which are evaporated on a planarization layer on top of the substrate through a suitable mask. The alignment accuracy between the alignment marks and the waveguide cores is better than $5 \mu \mathrm{m}$. This integrated structure supresses the need for an extra active or passive alignment step as is the case for pluggable coupling structures.

A $\mathrm{KrF}$ excimer laser $(248 \mathrm{~nm})$ is used for the ablation of the $45^{\circ}$ facets of the micromirrors. The excimer laser setup is schematically shown in Fig. 1. Polymer materials typically show a high absorption in the UV-region which allows for a clean ablation with low deposition of debris. During the processing, the sample is placed on a computer-controlled translation stage which has an accuracy of $1 \mu \mathrm{m}$. The laser beam can be tilted with respect to the sample, which eases the structuring of angled features considerably. The sample can thus stay horizontally on the translation stage during the ablation of the mirrors.

There is always a certain degree of tapering during the ablation which can be measured and consequently corrected for. The laser beam is sent through a rectangular aperture and projected onto the sample with a demagnification of ten. The formed cavity contains two interfaces with a different slope. The slope of the first interface, which is first hit by the light beam propagating through the waveguide, is steeper than the second one because of the tapering that occurs during the ablation, as can be seen in Fig. 2. Both interfaces can be used to deflect the light beam. In the first case, the light deflection occurs through the total internal reflection at the polymer-air interface. We study the use of the second interface as mirror facet. This mirror is embedded into the optical layer and thus protected from moist and dust intrusion and can be used in a very flexible way. The tilt angle of the excimer laser beam has been optimized to obtain a $45^{\circ}$ angle for the mirror facet. The

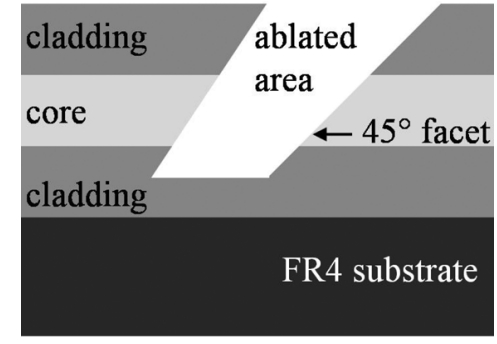

(a)

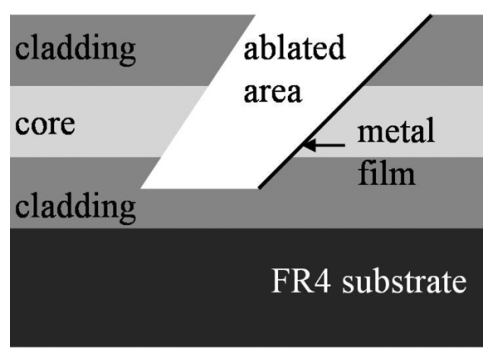

(b)

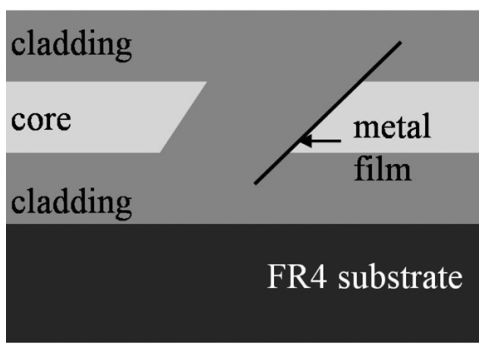

(c)

Fig. 2. Fabrication process of metallized $45^{\circ}$ micromirror. (a) Ablation $45^{\circ}$ facet. (b) Ti-Au coating of facet (c) Filling of ablated area with cladding material.

ablation parameters (pulse energy and repetition rate) and size of the mask have been optimized to ensure minimal surface roughness of the ablated facet.

The fabrication of the mirror requires three processing steps, as shown in Fig. 2. First, the $45^{\circ}$ facet is ablated. The facet is subsequently coated with a 50 -nm-thick layer of sputtered $\mathrm{Ti}$, to improve adhesion to the polymer material, and a 500-nmthick layer of evaporated $\mathrm{Au}$, to guarantee a high reflectivity. The sample is placed under a $45^{\circ}$ angle during the coating step and covered with a mask with openings at the position of the mirror facets. The last step consists of the filling of the ablated trench with cladding material.

The experimental results shown in Fig. 3 clearly show the good coverage of the facet with the metal coating and the good filling of the ablated area. The mirrors were ablated with a pulse energy of $3 \mathrm{~mJ}$, a repetition rate of $200 \mathrm{~Hz}$, and 425 pulses. However, the minimal pulse energy of the $\mathrm{KrF}$ excimer laser in our setup is $6 \mathrm{~mJ}$; therefore, an attenuator is placed in the laser beam path to tune the pulse energy according to wish. The used rectangular aperture has a dimension of $800 \mu \mathrm{m} \times 3000 \mu \mathrm{m}$.

The surface root-mean-square (rms) roughness of the ablated $45^{\circ}$ facet has been measured with an optical noncontact profiler (Wyko NT3300). The average surface roughness measured for the different optical materials, measured on a scan area of 


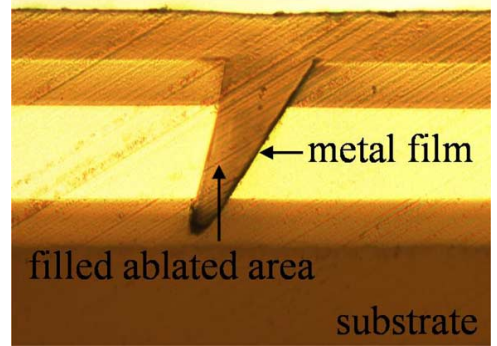

Fig. 3. Cross section of a metallized laser ablated micromirror.

TABLE II

SURFACE ROUGHNESS OF ABLATED $45^{\circ}$ FACET

\begin{tabular}{|c||c|}
\hline Optical material & RMS Surface Roughness (nm) \\
\hline Truemode Backplane $^{T M}$ Polymer & 61 \\
\hline Epocore/Epoclad & 70 \\
\hline
\end{tabular}

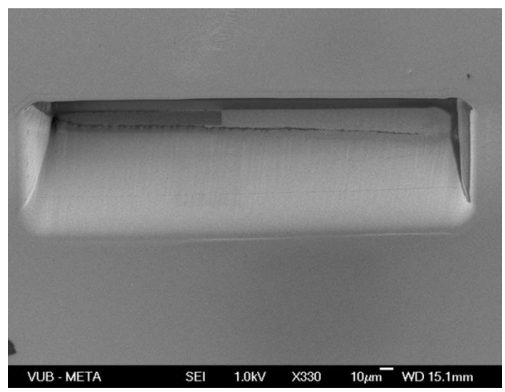

Fig. 4. SEM image showing the top view of a laser ablated $45^{\circ}$ facet structured in Truemode. The tapering at the bottom of the ablated trench is caused by inhomogeneities in the laser beam.

$46 \mu \mathrm{m} \times 109 \mu \mathrm{m}$, is given in Table II. The angle of the micromirror has been controlled with a stylus profiler (Dektak); the $45^{\circ}$ angle of the mirror facet has an accuracy of $\pm 1^{\circ}$ and a high reproducibility. Scanning electron microscope (SEM) images confirm the smooth surface of the ablated mirrors which is needed to guarantee a low scattering loss, as shown in Fig. 4.

The surface corrugation of the top cladding layer, caused by embedding a $45^{\circ}$ micromirror, has been measured with a noncontact profiler. The surface profile of the top cladding layer is shown in Fig. 5. The corrugation for a 50- $\mu$ m-thick top cladding layer has been measured to be $2 \mu \mathrm{m}$. This is acceptable in view of the twist and bow that the FR4 substrate typically shows. In case an extra $50-\mu \mathrm{m}$-thick cladding layer is added, this corrugation is limited to $200 \mathrm{~nm}$.

The metallized micromirrors have been subjected to a Telcordia $85 / 85$ stability test, during which they were put in a climate cabinet at $85^{\circ} \mathrm{C}$ and $85 \%$ relative humidity. The mechanical properties (adhesion of metal coating to polymer material, absence of air bubbles in the filled cavity, absence of cracks) of the mirrors were maintained.

\section{CONCLUSION}

We have successfully demonstrated the structuring of metallized 45 micromirrors, which are used to deflect the light beam

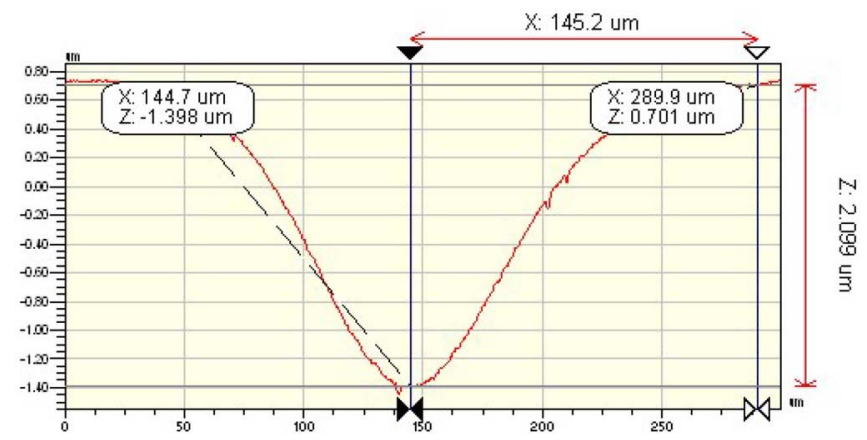

Fig. 5. Surface corrugation of top cladding layer when embedding metallized $45^{\circ}$ micromirror.

over $90^{\circ}$, into two different commercially available polymer materials. Both materials, Truemode and Epocore, give comparable results. The use of laser ablation allows for the direct integration of the mirrors with the optical waveguides, which guarantees a good alignment between the two. The mirrors have been characterized with surface roughness measurements and stylus profile measurements. The surface roughness of the $45^{\circ}$ facet is approximately $60-\mathrm{nm}$ rms for the Truemode material and 70-nm rms for the Epocore material. The angle accuracy of the $45^{\circ}$ facet has been measured to be better than $2^{\circ}$ and has a high reproducibility. The surface corrugation of the top cladding layer caused by embedding the micromirror is approximately $2 \mu \mathrm{m}$, which is acceptable in view of the deformation that the FR4 substrate typically shows. The advantage of using laser ablation is the fact that it is compatible with PCB manufacturing and already used for the drilling of microvias in high density boards. The mirror fabrication can, thus, be adopted into the existing processes in a very straightforward and cost-effective way.

\section{REFERENCES}

[1] D. Miller and H. Ozaktas, "Limit to the bit-rate capacity of electrical interconnects from the aspect ratio of the system architecture," J. Parallel Distributed Computing, vol. 41, no. 1, pp. 42-52, 1997.

[2] A. Glebov, M. G. Lee, S. Aoki, D. Kudzuma, J. Roman, M. Peters, L. Huang, D. S. Zhou, and K. Yokouchi, "Integrated waveguide microoptic elements for 3-D routing in board-level optical interconnects," Proc. SPIE, vol. 6126, no. 61260N, 2006.

[3] W.-C. Chuang, C.-T. Ho, and R. F. Shyu, "Fabrication of polymer waveguides using a molding process," Opt. Eng., vol. 45, no. 10, pp. 103401-103401, Oct. 2006.

[4] H. Schröder, J. Bauer, F. Ebling, M. Franke, A. Beier, P. Demmer, W. Süllau, J. Kostelnik, R. Mödinger, K. Pfeiffer, U. Ostrzinski, and E. Griese, "Waveguide and packaging technology for optical backplanes and hybrid electrical-optical circuit boards," Proc. SPIE, vol. 6124, no. 612407, 2006.

[5] G. Van Steenberge, N. Hendrickx, E. Bosman, J. Van Erps, H. Thienpont, and P. V. Daele, "Laser ablation of parallel optical interconnect waveguides," IEEE Photon. Technol. Lett., vol. 18, no. 9, pp. 1106-1108, May 1, 2006.

[6] O. Parriaux, V. A. Sychugov, and A. V. Tishchenko, "Coupling gratings as waveguide functional elements," Pure Appl. Opt., vol. 5, pp. 453-469.

[7] A. Glebov, J. Roman, M. G. Lee, and K. Yokouchi, "Optical interconnect modules with fully integrated reflector mirrors," IEEE Photon. Technol. Lett., vol. 17, no. 7, pp. 1540-1542, Jul. 2005.

[8] F. Tooley et al., "Optically written polymers used as optical interconnects and for hybridisation," Opt. Mater., vol. 17, pp. 235-241, 2001. 